\title{
Patient-Entered Wellness Data and Tailored Electronic Recommendations Increase Preventive Care
}

\author{
Julie Foucher-Urcuyo, BS, David Longworth, MD, Michael Roizen, MD, Bo Hu, PhD, \\ and Michael B. Rothberg, MD, MPH
}

Purpose: We investigated whether a tool using patient-entered wellness data to generate tailored electronic recommendations improved preventive care delivery.

Methods: We conducted a mixed-methods retrospective study of primary care encounters utilizing an Integrated Wellness Tool with a matched-comparison before-and-after study design. Encounters took place at a single clinic within the Cleveland Clinic Health System. The primary outcome was preventive orders placed. Index patients were matched, based on propensity scores, with comparison patients seen in the same clinic several months earlier.

Results: Five providers conducted 863 patient encounters using the tool during the study period. During encounters using the tool, providers placed more orders for smoking cessation programs $(2.4$ vs $0.5 \%, P<.01)$, lifestyle medicine $(2.4$ vs $0 \%, P<.01)$ and psychology $(2.3$ vs $1.0 \%, P=.04)$ consults, online nutrition $(2.4$ vs $1.4 \%, P=.04)$ and stress management $(5.5$ vs $0.9 \%, P<.01)$ programs, spirometry $(5.9$ vs $1.7 \%, P<.01)$ and polysomnography $(6.3$ vs $1.3 \%, P<.01)$ tests, and antidepressant $(7.2$ vs $3.9 \%, P=.01)$ and hypnotic $(2.2$ vs $0.7 \%, P=.01)$ medications when compared with matched encounters.

Conclusions: Patients are willing to enter lifestyle data, and these data influence provider orders. (J Am Board Fam Med 2017;30:350-361.)

Keywords: Counseling, Life Style, Preventive Medicine, Primary Health Care, Quality of Health Care, Retrospective Studies

Modifiable behavioral factors confer the greatest risk for chronic disability and account for the leading causes of mortality in the United States. ${ }^{1,2}$ A primary care visit provides an opportunity to promote behavior change, and a majority of patients expect their primary care providers to help with lifestyle behaviors. ${ }^{3}$ Despite this, recommended counseling and education is delivered only $18 \%$ of

This article was externally peer reviewed.

Submitted 19 July 2016; revised 21 December 2016; accepted 23 January 2017.

From the Lerner College of Medicine (JF-U), the Wellness Institute (MR), the Department of Internal Medicine and Medicine Institute Center for Value-Based Care Research (MBR), and Quantitative Health Science (BH), Cleveland Clinic, Cleveland, Ohio; and the Division of Primary Care, Lahey Health, Burlington, MA (DL).

Funding: none.

Conflict of interest: none declared.

Corresponding author: Julie Foucher-Urcuyo, BS, Cleveland Clinic, 9500 Euclid Ave., Cleveland, OH 44195 (Email: fouchej@ccf.org). the time. ${ }^{4}$ One often-cited barrier is the lack of organized systems to support the delivery of preventive services. ${ }^{5-8}$ With improved insurance coverage for preventive services, systems to efficiently identify patients' needs and facilitate delivery of the appropriate education, support, and follow-up resources are necessary. ${ }^{8,9}$ The collection of patiententered lifestyle risk data could facilitate targeted lifestyle discussions between caregiver and patient, and link to order sets to expedite appropriate management and/or behavior change. ${ }^{10}$

The Integrated Wellness Tool (IWT) combines patient-entered wellness data with clinical data from the electronic medical record to provide risk scores and clinical decision support in the areas of nutrition, stress, exercise, depression, sleep, and breathing. This tool was designed and piloted in a single primary care clinic during the fall of 2013, and we conducted a retrospective cohort study of 
Figure 1. Integrated Wellness Tool (IWT) provider electronic medical record interface. This interface may be viewed in the electronic medical record by providers after patients have completed the IWT. Risk scores are displayed for each wellness area, allowing providers to focus on those areas with the highest risk during the patient encounter. Providers may review and adjust patients' individual answers to the questionnaires and mark each area as "reviewed" using this interface. All patients automatically receive informational handouts tailored to their risk score in each wellness area. BMI, body mass index; COPD, Chronic Obstructive Pulmonary Disease.

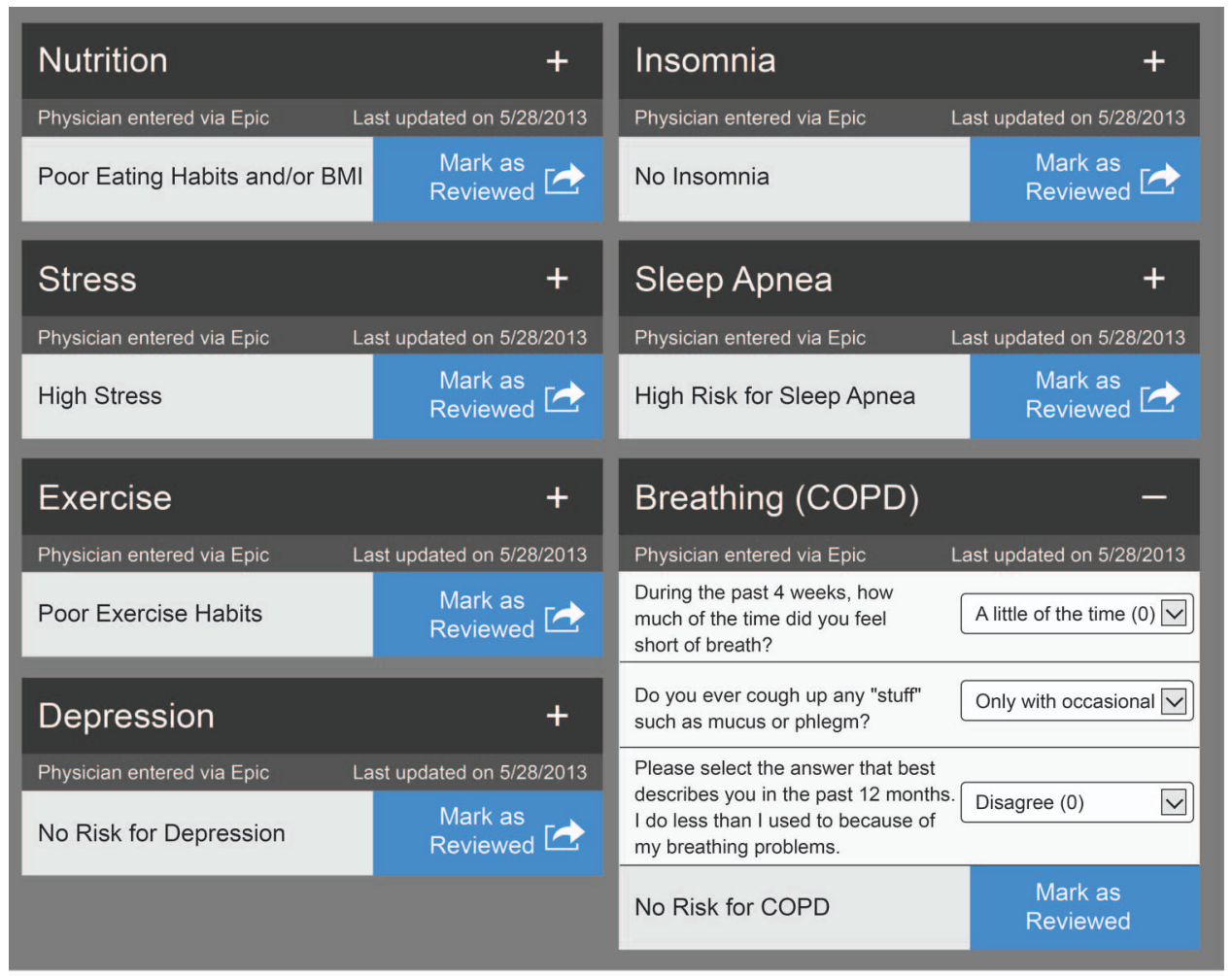

CCF@2017

encounters using the tool during this period. Specifically, we examined the effects of the IWT on providers' preventive care order placement and on patient and provider perceptions of the tool.

\section{Methods}

We conducted a mixed-methods study including a retrospective chart review of primary care encounters using a matched-comparison, before-and-after study design. We also performed qualitative interviews with providers. The study was approved by the Cleveland Clinic Institutional Review Board. Informed consent was obtained before conducting interviews with providers.

\section{The Integrated Wellness Tool}

The IWT collects patient-entered data electronically and synthesizes it with data (age, smoking status, and body mass index) from the electronic medical record (EPIC Systems, Verona, WI) to provide clinical decision support at the point of care. Using a tablet device, patients complete brief questionnaires in the waiting room, and the IWT generates a risk score for each of the following areas: nutrition, stress, ${ }^{11,12}$ exercise,${ }^{13}$ depression, ${ }^{14}$ insomnia, ${ }^{15}$ sleep apnea, ${ }^{16}$ and breathing. ${ }^{17}$ When providers open a patient's electronic chart, they are prompted to review these risk scores (Figure 1), clarify them during discussion with the patient, and mark them as "reviewed." The questions and order sets that comprise the IWT were constructed by a group of caregivers from 10 specialties, with experience in questionnaire design, behavior modification, patient education, laboratory data extraction, risk analysis, and order set design. Based on the risk scores, the provider may be prompted to order a 
screening test, consult, or treatment. The questionnaire, risk score calculations, and recommendations for nutrition are included in Appendix 1. All patients who use the IWT receive printed informational handouts tailored to their individual risk scores after the visit.

\section{Study Setting and Participants}

Between June 25 and September 4, 2013, the IWT was pilot-tested in a primary care clinic within the Cleveland Clinic Health System. The IWT was offered once to all patients presenting to the clinic during this time period, except those who made urgent appointments or who arrived late for their appointments. Front desk staff asked patients whether they would be willing to complete a wellness questionnaire on an iPad at check-in, and questions were answered in the waiting room. Six iPad devices were available to enable multiple patients to complete the questionnaire simultaneously. All encounters in which the IWT was used during this time were included in our study and comprised the "post-IWT" group. Matched comparison patients were selected from the same clinic several months before, forming the "pre-IWT" group. All encounters occurring at this clinic between February and April 2013 were included in the pre-IWT group. Urgent encounters, encounters without a recorded height and weight, and repeat visits during the study period were excluded. To control for temporal changes in the health system, we performed the same analysis at 2 similar clinics that did not use the IWT during either of these time periods ("comparison pre" and "comparison post” groups). Encounters were matched sequentially to the encounters in the post-IWT group using propensity scores. Patient followthrough with selected orders was measured and defined as screening test completion (spirometry, polysomnography) or attendance for at least 1 session with a consultant. All providers at the intervention practice were included and participated in the qualitative interviews.

\section{Data Collection}

Patient demographics and order placement were extracted from the electronic medical record (EPIC Systems). Orders included spirometry and polysomnography, consults (smoking cessation, nutrition therapy, psychology, psychiatry, sleep medicine, integrative medicine, lifestyle medicine), online programs available for purchase through the Cleveland Clinic Wellness website (Go! Foods for You, Stress Free Now, Go! To Sleep), and prescriptions (smoking cessation drugs, albuterol, antidepressants, and insomnia drugs). Orders placed within 1 week of the index encounter were included. Medication orders included those for new medications and those changing the dose of an existing medication.

Data from the IWT were stored outside the electronic medical record and collected separately. These included answers to the IWT questionnaires and an ease-of-use survey, as well as whether the provider had marked responses as "reviewed." Chart reviews were conducted by a single investigator (JF-U) to assess patient follow-through with selected orders.

Provider perceptions were obtained through qualitative semistructured interviews. Interviews were audio-recorded, transcribed, and coded by the interviewer (JF-U).

\section{Data Analysis}

Descriptive statistics were used to summarize patient characteristics, and 2-group comparisons were performed using a $t$ test or $\chi^{2}$ test, as appropriate. Comparison groups of patient encounters were matched with those from the experimental group in a 1:1 ratio using propensity scores. Propensity scores were based on age, sex, race, smoking status, and comorbid diagnoses (type 2 diabetes, hypertension, chronic obstructive pulmonary disease, sleep apnea, depression, and cardiovascular disease). The pre-IWT and comparison post groups were each matched to the post-IWT group, and then the comparison pre group was matched to the comparison post group. A $\chi^{2}$ test for proportions or the Fisher exact test (in the case of a small sample size) was used to assess differences in order placement from the before to after periods for all orders in the comparison and IWT groups. Logistic regression was used to adjust the comparisons for patient characteristics that differed between groups after matching. All analyses were conducted using JMP Pro (version 10.0), and statistical significance was established with a 2 -sided $P$ value $<.05$.

Qualitative data were reviewed and coded using NVivo (version 10.1.3) by a single investigator (JF-U) in order to identify emerging themes in an iterative manner. Potential themes and supporting quotations were discussed with a second investiga- 
Table 1. Characteristics of Patients Who Participated in the Integrated Wellness Tool (IWT) Pilot and Matched Comparison Encounters

\begin{tabular}{|c|c|c|c|c|c|c|}
\hline & \multicolumn{3}{|c|}{ Comparison Group } & \multicolumn{3}{|c|}{ IWT Pilot } \\
\hline & $\begin{array}{c}\text { Pre }^{*} \\
(\mathrm{n}=863)\end{array}$ & $\begin{array}{c}\text { Post }^{\dagger} \\
(\mathrm{n}=863)\end{array}$ & $P$ Value & $\begin{array}{c}\text { Pre }^{*} \\
(\mathrm{n}=863)\end{array}$ & $\begin{array}{c}\text { Post }^{\dagger} \\
(\mathrm{n}=863)\end{array}$ & $P$ Value \\
\hline Age, years $($ mean $\pm \mathrm{SD})$ & $60.7 \pm 15.5$ & $60.7 \pm 16.6$ & .95 & $57.7 \pm 16.8$ & $60.7 \pm 14.9$ & $<.01$ \\
\hline Sex & & & .96 & & & .10 \\
\hline Female & $566(65.6)$ & $565(65.5)$ & & $551(65.9)$ & $583(67.6)$ & \\
\hline Male & $297(34.4)$ & $298(34.5)$ & & $312(36.2)$ & $280(32.4)$ & \\
\hline Race & & & .42 & & & .39 \\
\hline Black & $59(6.8)$ & $61(7.1)$ & & $71(8.2)$ & $60(7.0)$ & \\
\hline White & $762(88.3)$ & $771(89.3)$ & & $756(87.6)$ & $774(89.7)$ & \\
\hline Other & $42(4.9)$ & $31(3.6)$ & & $36(4.2)$ & $29(3.4)$ & \\
\hline Ethnicity & & & .80 & & & .59 \\
\hline Hispanic & $8(0.9)$ & $10(1.2)$ & & $2(0.2)$ & $1(0.1)$ & \\
\hline Not Hispanic & $836(96.9)$ & $831(96.3)$ & & $836(96.9)$ & $842(97.6)$ & \\
\hline Other/unknown & $19(2.2)$ & $22(2.6)$ & & $25(2.9)$ & $20(2.3)$ & \\
\hline $\mathrm{BMI}, \mathrm{kg} / \mathrm{m}^{2}($ mean $\pm \mathrm{SD})$ & $29.8 \pm 7.0$ & $29.0 \pm 7.0$ & .02 & $28.5 \pm 6.2$ & $28.9 \pm 6.3$ & .19 \\
\hline Smoking status & & & .88 & & & .37 \\
\hline Current & $71(8.2)$ & $70(8.1)$ & & $61(7.1)$ & $70(8.1)$ & \\
\hline Former & $302(35.0)$ & $312(36.2)$ & & $326(37.8)$ & $306(35.5)$ & \\
\hline Never & $490(56.8)$ & $481(55.7)$ & & $474(54.9)$ & $487(56.4)$ & \\
\hline Never assessed & $0(0)$ & $0(0)$ & & $2(0.2)$ & $0(0)$ & \\
\hline \multicolumn{7}{|l|}{ Comorbidities } \\
\hline Type 2 diabetes & $197(22.8)$ & $201(23.3)$ & .82 & $156(18.1)$ & $183(21.2)$ & .10 \\
\hline Hypertension & $523(60.6)$ & $521(60.4)$ & .92 & $486(56.3)$ & $530(61.4)$ & .03 \\
\hline COPD & $62(7.2)$ & $66(7.7)$ & .71 & $56(6.5)$ & $72(8.3)$ & .14 \\
\hline Sleep apnea & $206(23.9)$ & $203(23.5)$ & .87 & $122(14.1)$ & $176(20.4)$ & $<.01$ \\
\hline Insomnia & $28(3.2)$ & $22(2.6)$ & .39 & $19(2.2)$ & $23(2.7)$ & .53 \\
\hline Anxiety & $212(24.6)$ & $201(23.3)$ & .53 & $199(23.1)$ & $200(23.2)$ & .95 \\
\hline Depression & $214(24.8)$ & $226(26.2)$ & .51 & $213(24.7)$ & $236(27.4)$ & .21 \\
\hline Cardiovascular disease & $273(31.6)$ & $269(31.2)$ & .84 & $239(27.7)$ & $277(32.1)$ & .05 \\
\hline
\end{tabular}

Data are $\mathrm{n}(\%)$ unless otherwise indicated.

*Patients from encounters matched to Integrated Wellness Tool (IWT) pilot encounters from the same practice (IWT pilot) and comparison practices (comparison group) that took place between February 11 and April 24, 2013.

${ }^{\dagger}$ Patients from IWT pilot encounters (IWT pilot) and matched comparison encounters (comparison group) that took place between June 25 and September 4, 2013.

COPD, chronic obstructive pulmonary disease; SD, standard deviation; BMI, body mass index.

tor (MR), who suggested additional classification until consensus was reached. Final themes were shared with 4 of the interviewees, who confirmed their accuracy and that nothing important was missed. Representative quotations were chosen by both investigators to demonstrate themes.

\section{Results}

\section{Patient and Provider Characteristics}

Five providers ( 4 physicians and 1 nurse practitioner) participated in 863 patient encounters during the IWT pilot period. They were $48.6 \pm 6.6$ years old, on average, mostly women (80\%), and had spent an av- erage of $19.8 \pm 8.8$ years in practice. Three providers reviewed $>90 \%$ of their patients' IWT results, whereas the other 2 providers reviewed these results $<50 \%$ of the time. The comparison pre $(\mathrm{n}=4006)$, comparison post $(\mathrm{n}=5019)$, and pre-IWT $(\mathrm{N}=$ 1065) groups each had 863 encounters after propensity score matching. Patient characteristics are shown in Table 1. A few variables had small but statistically significant differences after matching.

Figure 2 displays patient risk scores by wellness category. Almost all patients (97\%) exhibited greater than mild risk in at least 1 category. Nutrition $(89 \%)$ and stress $(53 \%)$ represented the areas 
Figure 2. Patient risk by wellness category, captured using the Integrated Wellness Tool (IWT). Risk scores are determined by patient responses to IWT questionnaires during the pilot (June 25 to September 4, 2013). Total responses for the various questionnaires were 702 for chronic obstructive pulmonary disease (COPD), 839 for nutrition, 805 for stress, 825 for exercise, 789 for depression, 734 for insomnia, and 621 for sleep apnea.

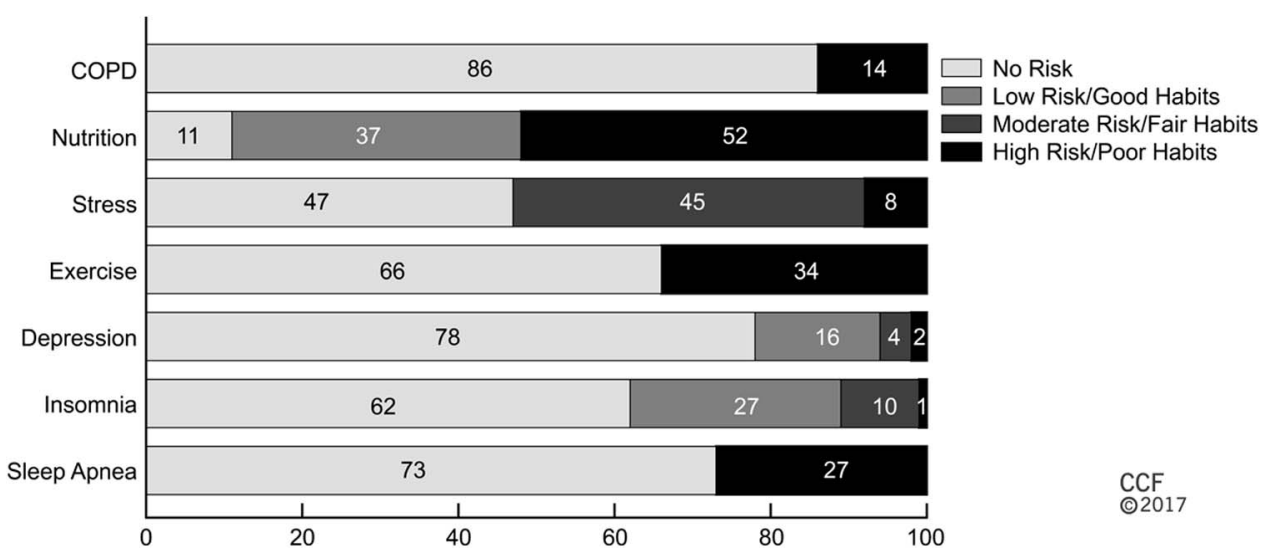

with the greatest percentage of scores that were "mild risk" or greater.

\section{Effect on Order Placement}

Of 5134 total orders prompted by the IWT based on patients' risk scores in each of the wellness areas, 293 were placed by providers (5.7\%). This increased to $7.8 \%(270 / 3455)$ when looking only at risk scores that had been marked as "reviewed" by providers. The specific percentages varied by order (Appendix 2). After implementation of the IWT, the placement of most orders at the intervention site increased-some, such as consult to lifestyle medicine, as much as 5 -fold (Table 2). Orders with the greatest increase in placement included polysomnography, consults to Stress Free Now, and spirometry. Orders for albuterol, drugs for smoking cessation, and consults to integrative and behavioral sleep medicine did not increase. None of the target orders in the comparison group sites increased during the study period (Table 2).

\section{Patient Follow-Through}

Patient follow-through was low overall (Table 3). Of the patients who completed spirometry, 28\% had abnormal results. All patients who underwent polysomnography had an abnormal result.

\section{Patient Perceptions}

Of 699 patients who completed the ease-of-use survey, almost all patients found the IWT easy to use $(\mathrm{n}=688[99 \%])$, did not require help $(\mathrm{n}=668$
[96\%]), and stated that they would use the tool again $(n=658$ [94\%]). Similar observations were made by patients $>80$ years of age $(n=56)$. Most patients $(\mathrm{n}=645$ [92\%]) indicated that the IWT would help their provider understand their current state of health to some extent.

\section{Qualitative Assessment}

Providers generally perceived wellness as important to their role in primary care. One stated "We think of ourselves as specializing in [wellness]." Before the IWT, providers used a variety of methods to assess and document wellness behaviors, and were confident in their abilities to address wellness. Though curious to see patients' reactions to the tool, providers had concerns about changing their routine, learning new technology, and increased demands on their time with the IWT.

Providers also found the IWT easy to use: "It was actually very simple to use. I had no trouble with it at all." Providers were not surprised by their patients' risk scores, stating that the IWT "did not provide any new information." They found the tool most useful for new patient encounters and physical exams. Providers found that the IWT generated more discussion and increased patients' involvement in their care. One provider reflected on the utility of the IWT data in addressing chronic pain and fatigue:

There's been several patient encounters where patients come in with chronic pain, chronic fatigue complaints, and their depression scores 
Table 2. Frequency of Order Placement by Primary Care Providers During the Integrated Wellness Tool Pilot and from Matched Comparison Groups

\begin{tabular}{|c|c|c|c|c|c|c|}
\hline \multirow[b]{2}{*}{ Order } & \multicolumn{3}{|c|}{ Comparison Group } & \multicolumn{3}{|c|}{ IWT Pilot } \\
\hline & $\operatorname{Pre}^{*}$ & $\operatorname{Post}^{\dagger}$ & $P$ Value & Pre* & $\operatorname{Post}^{\dagger}$ & $P$ Value \\
\hline \multicolumn{7}{|l|}{ Breathing (COPD) } \\
\hline Spirometry & $3(0.4)$ & $3(0.4)$ & .66 & $15(1.7)$ & $51(5.9)$ & $<.01$ \\
\hline Consult to smoking cessation & $1(0.1)$ & $2(0.2)$ & .50 & $4(0.5)$ & $21(2.4)$ & $<.01$ \\
\hline Smoking cessation drug order & $4(0.5)$ & $8(0.9)$ & .19 & $11(1.3)$ & $10(1.2)$ & .91 \\
\hline Albuterol order & $18(0.2)$ & $9(1.0)$ & .08 & $15(1.7)$ & $14(1.6)$ & .97 \\
\hline \multicolumn{7}{|l|}{ Nutrition } \\
\hline Consult to Go! Foods For You & $2(0.2)$ & $1(0.1)$ & .88 & $12(1.4)$ & $21(2.4)$ & .04 \\
\hline Consult to nutrition therapy & $7(0.8)$ & $4(0.5)$ & .89 & $17(2.0)$ & $23(2.7)$ & .30 \\
\hline \multicolumn{7}{|l|}{ Stress } \\
\hline Consult to Stress Free Now! & $0(0)$ & $1(0.1)$ & .50 & $8(0.9)$ & $47(5.5)$ & $<.01$ \\
\hline Consult to integrative medicine & $0(0)$ & $1(0.1)$ & .50 & $0(0)$ & $2(0.2)$ & 1.00 \\
\hline \multicolumn{7}{|l|}{ Exercise } \\
\hline Consult to lifestyle medicine & $0(0)$ & $0(0)$ & - & $0(0)$ & $21(2.4)$ & $<.01$ \\
\hline \multicolumn{7}{|l|}{ Depression } \\
\hline Consult to psychology & $7(0.8)$ & $12(1.4)$ & .25 & $9(1.0)$ & $20(2.3)$ & .04 \\
\hline Consult to psychiatry & $4(0.5)$ & $9(1.0)$ & .13 & $6(0.7)$ & $14(1.6)$ & .07 \\
\hline Antidepressant drug order & $38(1.5)$ & $46(5.3)$ & .37 & $34(3.9)$ & $62(7.2)$ & .01 \\
\hline \multicolumn{7}{|l|}{ Insomnia } \\
\hline Consult to Go! To Sleep & $0(0)$ & $0(0)$ & - & $6(0.7)$ & $18(2.1)$ & .01 \\
\hline \multicolumn{7}{|c|}{ Consult to behavioral sleep medicine } \\
\hline Group & $0(0)$ & $0(0)$ & - & $0(0)$ & $1(0.1)$ & 1.00 \\
\hline Individual & $0(0)$ & $0(0)$ & - & $0(0)$ & $2(0.2)$ & 1.00 \\
\hline Insomnia drug order & $8(1.5)$ & $13(4.4)$ & .27 & $6(0.7)$ & $19(2.2)$ & .01 \\
\hline \multicolumn{7}{|l|}{ Sleep apnea } \\
\hline Polysomnogram & $11(1.3)$ & $13(1.5)$ & .68 & $11(1.3)$ & $54(6.3)$ & $<.01$ \\
\hline Consult to sleep medicine & $2(0.2)$ & $5(0.6)$ & .23 & $6(0.7)$ & $8(0.9)$ & .76 \\
\hline
\end{tabular}

Data are no. of encounters with order (percentage of 863 total encounters per group), unless otherwise indicated. All comparisons were adjusted for age and sleep apnea, hypertension, and cardiovascular disease status.

COPD, chronic obstructive pulmonary disease; IWT, Integrated Wellness Tool.

*Number of patients whose risk score prompted the order using the Integrated Wellness Tool.

${ }^{\dagger}$ Percentage values are the proportions of the totals.

are high, their stress scores are high, and it's actually given me some objective data to turn the computer screen to them and say hey, do you think this might be contributing? So that is what I found really useful and I did not anticipate that that was going to be the case. It actually makes it easier to address what the real issues are. That way we do not have to do 10 more tests to figure out the chronic fatigue.

Providers reflected that discussing wellness required time. However, in some situations such as screening, providers found the IWT to streamline the ordering process: "For the [chronic obstructive pulmonary disease] ones that actually the screen was positive for, and I was able to order the [pul- monary function test]s ... all in 1 click .... That was really helpful."

Overall, providers did not recognize much patient follow-through with lifestyle recommendations after using the IWT: "I did not find that it changed behavior." Because of this, they did not perceive the tool to have improved their ability to care for patients: "Personally I do not think it really enhances how I take care of them, but maybe their buy-in to wellness is enhanced with that exercise. I think that is the best aspect of it."

\section{Discussion}

This mixed-methods retrospective cohort study of 863 patient encounters conducted by 5 providers 
Table 3. Order Placement and Follow-Through for Patients with Elevated Integrated Wellness Tool Risk Scores, By Wellness Area

\begin{tabular}{|c|c|c|c|c|c|}
\hline Test & $\begin{array}{c}\text { Completed } \\
\text { Questionnaires, } \mathrm{n}\end{array}$ & $\begin{array}{l}\text { At Risk, } \\
\text { n (\%) }\end{array}$ & Order & Placed, n $(\%)^{\dagger}$ & Completed n $(\%)^{\dagger}$ \\
\hline \multirow[t]{2}{*}{ Smoking } & 863 & $70(8)$ & Smoking cessation & $21(30)$ & \\
\hline & & & Prescription & $5(7)$ & \\
\hline \multirow[t]{2}{*}{ COPD } & 702 & $98(14)$ & Albuterol & $4(4)$ & \\
\hline & & & Spirometry & $31(32)$ & $18(58)$ \\
\hline \multirow[t]{2}{*}{ Nutrition } & 839 & $749(89)$ & Go! Foods For You & $22(3)$ & \\
\hline & & & Nutrition therapy & $22(3)$ & $6(27)$ \\
\hline \multirow[t]{2}{*}{ Stress } & 805 & $428(53)$ & Stress Free Now & $40(9)$ & \\
\hline & & & Integrative medicine & $2(0.5)$ & $0(0)$ \\
\hline Exercise & 825 & $280(34)$ & Lifestyle medicine & $14(5)$ & $1(7)$ \\
\hline \multirow[t]{3}{*}{ Depression } & 789 & $175(22)$ & Psychology & $17(10)$ & $2(12)$ \\
\hline & & & Psychiatry & $11(6)$ & $1(9)$ \\
\hline & & & Prescription & $29(17)$ & \\
\hline \multirow[t]{4}{*}{ Insomnia } & 734 & $79(11)$ & Behavioral sleep medicine (group) & $1(1)$ & $0(0)$ \\
\hline & & & Behavioral sleep medicine (individual) & $2(3)$ & $0(0)$ \\
\hline & & & Go! To Sleep & $8(6)$ & \\
\hline & & & Prescription & $4(6)$ & \\
\hline \multirow[t]{2}{*}{ Sleep apnea } & 621 & $166(27)$ & Sleep medicine & $3(2)$ & $0(0)$ \\
\hline & & & Polysomnography & $42(25)$ & $13(31)$ \\
\hline
\end{tabular}

*Number of patients whose risk score prompted the order using the Integrated Wellness Tool.

${ }^{\dagger}$ Percentage values are the proportions of the totals.

COPD, chronic obstructive pulmonary disease.

using the IWT demonstrated that patients are willing to enter personal wellness data using standardized electronic questionnaires, and these data can influence providers' preventive care ordering patterns.

The feasibility of collecting patient-entered health data, including family history ${ }^{18}$ and lifestyle behaviors, ${ }^{19-22}$ in preparation for an annual wellness examination has been well documented. One study in a primary care setting found that patients were willing to complete questionnaires on mobile devices in the waiting room and this did not affect workflow. ${ }^{21}$ Although our study did not investigate the IWT's impact on workflow, patients and providers alike reported that it was easy to use.

Electronic reminders have shown promise for changing physician behavior. ${ }^{23}$ Point-of-care reminder systems generally improve adherence to processes of care by a small amount (median increase of $4 \%$ ). ${ }^{24}$ Larger effects (median increase of $12 \%$ ) have been noted for preventive care reminders. ${ }^{25,26}$ "Homegrown" clinical information systems have shown the largest improvements (median increase of $17 \%$ ), perhaps because they are better integrated into providers' workflow. ${ }^{24}$ We saw modest increases in the rate of provider order placement $(1.2 \%$, on average); however, the majority of interventions tested here were lifestyle interventions rather than standard-of-care screening tests. Referrals to consults such as psychology and psychiatry may have been low because of the limited availability of these resources within our health care system. Orders for screening tests showed larger increases (4.2\% for spirometry and $5.0 \%$ for polysomnography).

Interestingly, although providers in our study expressed that the IWT did not provide any "new information" or enhance the care they provided, they consistently placed more preventive care orders when using the tool. This behavior might be attributed to new information presented to the provider, or simply to reminding the provider of the condition when it came time to place orders. Of particular interest is the almost $400 \%$ increase in consults to smoking cessation with the IWT. Although smoking status was already documented in the electronic medical record and providers were presumably aware of it, they ordered fewer consults for tobacco treatment programs before the IWT. 
Few studies have integrated the collection of patient-entered data with provider reminders to improve recommendations for, discussions of, and actual preventive care delivery and patient behavior change. One study conducted in New Zealand demonstrated the feasibility of an electronic lifestyle assessment tool similar to the IWT. ${ }^{22}$ While the results of that assessment may be downloaded from a website to the electronic medical record by the provider, they do not drive automatic order prompts, thus increasing the steps required to implement a relevant care plan. Despite this difference, most patients in that study found the tool easy to use, and feedback from providers was positive.

The IWT differs from other health risk assessments in that it is focused on lifestyle information (as opposed to recommended screening), and it is generally physician-facing, meaning patients have few opportunities to interact or engage with their lifestyle data. A 5-level model for making information technology patient-centered ${ }^{27}$ proposes that an electronic tool must (1) collect patient-entered information, (2) integrate this information with existing clinical information, (3) interpret information for patients through a user-friendly interface, (4) provide individualized recommendations to patients based on risk profile and evidence-based guidelines, and (5) facilitate patient activation and engagement. While the IWT does provide individualized recommendations, it does so through the provider.

An alternative tool, MyPreventiveCare, which contains all the above-mentioned components, has been shown to improve preventive care delivery in an 8-practice pilot and is currently under investigation in a large clinical trial. ${ }^{28,29}$ Like other health risk assessments, MyPreventiveCare is focused on screening tests and immunizations rather than on lifestyle interventions. ${ }^{30,31}$ Allowing patients to access and interact directly with the IWT data may help to improve patient activation, leading to increased follow-through with orders and long-term lifestyle behavior change.

Interestingly, providers were more likely to recommend and patients more likely to complete recommended screening tests than lifestyle interventions. The reasons for this are unknown. It may relate to the 1-time nature of screening tests, or a belief that these interventions are more evidencebased or more likely to succeed.
The IWT incorporates several domains that have not previously been included in risk assessment tools. Both stress and sleep have a strong effect on health, ${ }^{32-34}$ yet they are rarely addressed in the primary care setting in an actionable way. ${ }^{36}$ Nutrition and physical activity are also important contributors to health, yet standard screening methods (other than body mass index) are not routinely recommended. ${ }^{36}$ Depression screening has been covered by Medicare since 2011 and is recommended for all adults in settings with effective follow-up supports. ${ }^{37}$ The IWT provides a systematic way to implement screening in all these areas and track changes in patients over time.

Our study has limitations. Although we examined a large number of encounters, our pilot included only 5 providers, limiting the conclusions we may draw from their ordering patterns and qualitative feedback. It seems that 3 of the 5 providers were more engaged than the other 2 in using the IWT based on the rate at which IWT results were marked as "reviewed." No differences in age, sex, years in practice, or qualitative themes were found between these 2 provider groups; however, 1 of the "less engaged" providers mentioned that she often did not know whether a patient had completed the IWT. This may further limit conclusions that may be drawn. This study focused on only preventive care delivery. Neither the appropriateness of this care, patient behavior change, nor change in health outcomes were assessed. In addition, we only measured preventive care delivery in the form of consults, screening tests, and treatments ordered. Changes in behavioral counseling may have occurred but were not measurable.

\section{Conclusion}

This pilot study demonstrates that an electronic tool can be used to routinely collect patiententered lifestyle data, and that these data can provide meaningful decision support to increase the delivery of preventive care. Future versions should include a patient portal allowing patients to interact with their results and providing educational information. This might increase patient activation and improve follow-through with providers' recommendations. In addition, subsequent studies should investigate the long-term effect of such tools on patients' behaviors and health outcomes. 
The authors thank MaryBeth Mercer, MPH, for her guidance during the qualitative portion of this study, and William Morris, MD, and the Cleveland Clinic Clinical Solutions Center for developing and allowing us to study the Integrated Wellness Tool.

To see this article online, please go to: bttp://jabfm.org/content/ 30/3/350.full.

\section{References}

1. Mokdad AH, Marks JS, Stroup DF, Gerberding JL. Actual causes of death in the United States, 2000. JAMA 2004;291:1238-45.

2. Yach D, Hawkes C, Gould CL, Hofman KJ. The global burden of chronic diseases: overcoming impediments to prevention and control. JAMA 2004; 291:2616-22.

3. Vogt TM, Hollis JF, Lichtenstein E, Stevens VJ, Glasgow R, Whitlock E. The medical care system and prevention: the need for a new paradigm. HMO Pract 1998;12:5-13.

4. McGlynn EA, Asch SM, Adams J, et al. The quality of health care delivered to adults in the United States. N Engl J Med 2003;348:2635-45.

5. Yarnall KSH, Pollak KI, Østbye T, Krause KM, Michener JL. Primary care: is there enough time for prevention? Am J Public Health 2003;93:635-41.

6. Thompson RS. What have HMOs learned about clinical prevention services? An examination of the experience at Group Health Cooperative of Puget Sound. Milbank Q 1996;74:469-509.

7. Solberg LI, Kottke TE, Brekke ML, Conn SA, Magnan S, Amundson G. The case of the missing clinical preventive services systems. Eff Clin Pract 1998;1: 33-8.

8. Whitlock EP, Orleans CT, Pender N, Allan J. Evaluating primary care behavioral counseling interventions: an evidence-based approach. Am J Prev Med 2002;22:267-84.

9. Solberg LI, Kottke TE, Brekke ML. Will primary care clinics organize themselves to improve the delivery of preventive services? A randomized controlled trial. Prev Med 1998;27:623-31.

10. Carey M, Noble N, Mansfield E, Waller A, Henskens F, Sanson-Fisher R. The role of eHealth in optimizing preventive care in the primary care setting. J Med Internet Res 2015;17:e126.

11. Cohen S, Kamarck T, Mermelstein R. A global measure of perceived stress. J Health Soc Behav 1983; 24:385-96.

12. Cohen S. Perceived stress in a probability sample of the United States. In: Spacapan S, Oskamp S, eds. The social psychology of health. The Claremont Symposium on Applied Social Psychology. Thousand Oaks, CA: Sage Publications;1988. pp. 31-67.

13. Garber CE, Blissmer B, Deschenes MR, et al. American College of Sports Medicine position stand. Quantity and quality of exercise for developing and maintaining cardiorespiratory, musculoskeletal, and neuromotor fitness in apparently healthy adults: guidance for prescribing exercise. Med Sci Sports Exerc 2011;43:1334-59.

14. Kroenke K, Spitzer RL, Williams JB. The PHQ-9: validity of a brief depression severity measure. J Gen Intern Med 2001;16:606-13.

15. Bastien CH, Vallières A, Morin CM. Validation of the Insomnia Severity Index as an outcome measure for insomnia research. Sleep Med 2001;2:297-307.

16. Chung F, Yegneswaran B, Liao P, et al. STOP questionnaire: a tool to screen patients for obstructive sleep apnea. Anesthesiology 2008;108:812-21.

17. Martinez FJ, Raczek AE, Seifer FD, et al. Development and initial validation of a self-scored COPD Population Screener Questionnaire (COPD-PS). COPD 2008;5:85-95.

18. Murray MF, Giovanni MA, Klinger E, et al. Comparing electronic health record portals to obtain patient-entered family health history in primary care. J Gen Intern Med 2013;28:1558-64.

19. Forjuoh SN, Ory MG, Wang S, des Bordes JK, Hong Y. Using the iPod touch for patient health behavior assessment and health promotion in primary care. JMIR Mhealth Uhealth 2014;2:e14.

20. Hess R, Santucci A, McTigue K, Fischer G, Kapoor W. Patient difficulty using tablet computers to screen in primary care. J Gen Intern Med 2008;23: 476-80.

21. Paul CL, Carey M, Yoong SL, D'Este C, Makeham $\mathrm{M}$, Henskens F. Access to chronic disease care in general practice: the acceptability of implementing systematic waiting-room screening using computerbased patient-reported risk status. Br J Gen Pract 2013;63:e620-6.

22. Goodyear-Smith F, Warren J, Bojic M, Chong A. eCHAT for lifestyle and mental health screening in primary care. Ann Fam Med 2013;11:460-6.

23. Grimshaw JM, Shirran L, Thomas R, et al. Changing provider behavior: an overview of systematic reviews of interventions. Med Care 2001;39(8 Suppl 2):II2-45.

24. Shojania KG, Jennings A, Mayhew A, Ramsay C, Eccles M, Grimshaw J. Effect of point-of-care computer reminders on physician behaviour: a systematic review. CMAJ 2010;182:E216-25.

25. Dexheimer JW, Talbot TR, Sanders DL, Rosenbloom ST, Aronsky D. Prompting clinicians about preventive care measures: a systematic review of randomized controlled trials. J Am Med Inform Assoc 2008;15:311-20.

26. Balas EA, Weingarten S, Garb CT, Blumenthal D, Boren SA, Brown GD. Improving preventive care by prompting physicians. Arch Intern Med 2000;160: 301-8.

27. Krist AH, Woolf SH. A vision for patient-centered health information systems. JAMA 2011;305: $300-1$. 
28. Krist AH, Peele E, Woolf SH, et al. Designing a patient-centered personal health record to promote preventive care. BMC Med Inform Decis Mak 2011; $11: 73$.

29. Krist AH, Aycock RA, Etz RS, et al. MyPreventiveCare: implementation and dissemination of an interactive preventive health record in three practicebased research networks serving disadvantaged patients-a randomized cluster trial. Implement Sci. 2014;9:181.

30. Krist AH, Woolf SH, Rothemich SF, et al. Interactive preventive health record to enhance delivery of recommended care: a randomized trial. Ann Fam Med 2012;10:312-9.

31. Krist AH, Woolf SH, Bello GA, et al. Engaging primary care patients to use a patient-centered personal health record. Ann Fam Med 2014;12:418-26.

32. Watson NF, Badr MS, Belenky G, et al. Recommended amount of sleep for a healthy adult: a joint consensus statement of the American Academy of
Sleep Medicine and Sleep Research Society. Sleep. 2015;38:843-4.

33. Booth J, Connelly L, Lawrence M, et al. Evidence of perceived psychosocial stress as a risk factor for stroke in adults: a meta-analysis. BMC Neurol. 2015; 15:233.

34. Younge JO, Wery MF, Gotink RA, et al. Webbased Mindfulness Intervention in Heart Disease: a randomized controlled trial. PloS One 2015;10: e0143843.

35. Sorscher AJ. How is your sleep: a neglected topic for health care screening. J Am Board Fam Med 2008; 21:141-8.

36. Yao A. Screening for and management of obesity in adults: U.S. Preventive Services Task Force recommendation statement: a policy review. Ann Med Surg (Lond) 2012;2:18-21.

37. O'Connor EA, Whitlock EP, Beil TL, Gaynes BN. Screening for depression in adult patients in primary care settings: a systematic evidence review. Ann Intern Med 2009;151:793-803. 


\section{Appendix 1}

Do you read ingredient labels to avoid added sugars and syrups before deciding on an item?

All the time

Most of the time

Some of the time

Never

How many servings ( 1 serving is approximately 1 handful) of fruits and vegetables do you eat a day, on average? Do not count juice or dried fruits.

$0-1$

2-3

$\geq 4$ 
Fair

Score: $11-20$ and BMI in category A or $<20$ and BMI in category B or C

Smartset recommendations: consult to nutrition therapy, consult to GO! Foods for You, Fair Eating Habits educational handout

Poor

Score: $>20$ and BMI in any category or $>1$ and BMI in category D or E

Smartset recommendations: consult to nutrition therapy, consult to GO! Foods for You, Poor Eating Habits educational handout

*Body mass index (BMI) data from the electronic medical record.

\section{Appendix 2}

Placement of Orders Recommended by the Integrated Wellness Tool, by Reviewed Status

\begin{tabular}{|c|c|c|c|}
\hline & Reviewed & Not Reviewed & $P$ Value \\
\hline \multicolumn{4}{|l|}{ Smoking } \\
\hline Consult to smoking cessation & $19(43)$ & $2(8)$ & .01 \\
\hline Smoking cessation prescription & $3(7)$ & $2(8)$ & .74 \\
\hline \multicolumn{4}{|l|}{ COPD } \\
\hline Spirometry & $29(41)$ & $2(7)$ & $<.01$ \\
\hline Albuterol prescription & $4(6)$ & $0(0)$ & .25 \\
\hline \multicolumn{4}{|l|}{ Nutrition } \\
\hline Consult to Go! Foods For You & $22(4)$ & $0(0)$ & $<.01$ \\
\hline Consult to nutrition therapy & $18(4)$ & $4(2)$ & .15 \\
\hline \multicolumn{4}{|l|}{ Stress } \\
\hline Consult to Stress Free Now & $47(8)$ & $0(0)$ & $<.01$ \\
\hline Consult to integrative medicine & $2(1)$ & $0(0)$ & .46 \\
\hline \multicolumn{4}{|l|}{ Exercise } \\
\hline Consult to lifestyle medicine & $13(7)$ & $1(1)$ & .03 \\
\hline \multicolumn{4}{|l|}{ Depression } \\
\hline Consult to psychology & $17(15)$ & $0(0)$ & $<.01$ \\
\hline Consult to psychiatry & $10(9)$ & $1(2)$ & .07 \\
\hline Antidepressant prescription* & $19(16)$ & $10(17)$ & .92 \\
\hline \multicolumn{4}{|l|}{ Insomnia } \\
\hline Consult to Go! To Sleep & $16(8)$ & $0(0)$ & .03 \\
\hline \multicolumn{4}{|c|}{ Consult to behavioral sleep medicine } \\
\hline Group & $1(2)$ & $0(0)$ & .68 \\
\hline Individual & $2(4)$ & $0(0)$ & .46 \\
\hline Insomnia prescription* & $4(7)$ & $0(0)$ & .21 \\
\hline \multicolumn{4}{|l|}{ Sleep apnea } \\
\hline Polysomnography & $41(36)$ & $1(2)$ & $<.01$ \\
\hline Consult to sleep medicine & $3(3)$ & $0(0)$ & .33 \\
\hline
\end{tabular}

Data are $\mathrm{n}(\%)$ unless otherwise indicated. Percentage values are the proportions of orders placed among those recommended by the Integrated Wellness Tool (IWT) that had been marked as reviewed/not reviewed by the provider using the IWT electronic medical record interface.

*Not included in Integrated Wellness Tool order recommendations.

COPD, chronic obstructive pulmonary disease. 